\title{
Temperature, hydric environment, and prior pathogen exposure alter the experimental severity of chytridiomycosis in boreal toads
}

\author{
Peter J. Murphy ${ }^{1,3, *}$, Sophie St-Hilaire ${ }^{1}$, Paul Stephen Corn $^{2}$ \\ ${ }^{1}$ Department of Biological Sciences, Idaho State University, 650 Memorial Dr., Pocatello, Idaho 83209-8007, USA \\ ${ }^{2}$ U.S. Geological Survey, Aldo Leopold Wilderness Research Institute, Missoula, Montana 59801, USA \\ ${ }^{3}$ Present address: Department of Natural Resources \& Environmental Science, MS 186, University of Nevada, Reno, \\ Nevada 89557-0210, USA
}

\begin{abstract}
Prevalence of the pathogen Batrachochytrium dendrobatidis $(B d)$, implicated in amphibian population declines worldwide, is associated with habitat moisture and temperature, but few studies have varied these factors and measured the response to infection in amphibian hosts. We evaluated how varying humidity, contact with water, and temperature affected the manifestation of chytridiomycosis in boreal toads Anaxyrus (Bufo) boreas boreas and how prior exposure to $B d$ affects the likelihood of survival after re-exposure, such as may occur seasonally in long-lived species. Humidity did not affect survival or the degree of $B d$ infection, but a longer time in contact with water increased the likelihood of mortality. After exposure to $\sim 10^{6} B d$ zoospores, all toads in continuous contact with water died within $30 \mathrm{~d}$. Moreover, $B d$-exposed toads that were disease-free after $64 \mathrm{~d}$ under dry conditions, developed lethal chytridiomycosis within $70 \mathrm{~d}$ of transfer to wet conditions. Toads in unheated aquaria (mean $=15^{\circ} \mathrm{C}$ ) survived less than $48 \mathrm{~d}$, while those in moderately heated aquaria $\left(\right.$ mean $=18^{\circ} \mathrm{C}$ ) survived $115 \mathrm{~d}$ post-exposure and exhibited behavioral fever, selecting warmer sites across a temperature gradient. We also found benefits of prior $B d$ infection: previously exposed toads survived 3 times longer than $B d$-naïve toads after re-exposure to $10^{6}$ zoospores (89 vs. $30 \mathrm{~d}$ ), but only when dry microenvironments were available. This study illustrates how the outcome of $B d$ infection in boreal toads is environmentally dependent: when continuously wet, high reinfection rates may overwhelm defenses, but periodic drying, moderate warming, and previous infection may allow infected toads to extend their survival.
\end{abstract}

KEY WORDS: Boreal toads $\cdot$ Disease severity $\cdot$ Chytridiomycosis $\cdot$ Temperature $\cdot$ Moisture $\cdot$ Acquired immunity

\section{INTRODUCTION}

Chytridiomycosis, an emergent skin disease caused by the fungus Batrachochytrium dendrobatidis $(B d)$, has been documented in over 200 amphibian species worldwide and has caused local extinctions and widespread population declines (Skerratt et al. 2007). Surveys have demonstrated that the prevalence of $B d$ infection increases in species inhabiting permanent water (Kriger \& Hero 2007, Brem \& Lips 2008), in species overwintering aquatically versus terrestrially (Longcore et al. 2007), and seasonally in cool months, both across species and within single populations (McDonald et al. 2005, Woodhams \& Alford 2005). Infection patterns in the wild are consistent with an aquatic infectious stage unable to survive desiccation (Longcore et al. 1999, Johnson et al. 2003). Likewise, $B d$ grows optimally at moderate temperatures (17 to $25^{\circ} \mathrm{C}$ ), with arrested growth at $28^{\circ} \mathrm{C}$, and death at $30^{\circ} \mathrm{C}$ (after 8 d; Piotrowski et al. 2004). The development of 
lethal chytridiomycosis, however, depends not only on $B d$, but on the host's immune response. Resistance to $B d$ has been linked to antimicrobial skin peptides and other hydrophobic molecules (Woodhams et al. 2007, Rollins-Smith et al. 2009) and cutaneous bacteria (Harris et al. 2006), both of which may change in effectiveness depending on body temperature and hydric environment (Matutte et al. 2000, Rollins-Smith et al. 2002).

Although the effects of varying temperature on chytridiomycosis have been studied experimentally, the outcomes in vivo have not always been consistent with the temperature optima of $B d$ in pure culture. For example, Carey et al. (2006) found no difference in survival time in infected boreal toads Anaxyrus boreas boreas housed at 12 and $23^{\circ} \mathrm{C}$, although $12^{\circ} \mathrm{C}$ is well below the optimal growth range of $B d$. Likewise, 2 studies have found that moderate changes in temperature within the optimal growth range of $B d$ (from 17 to $22-23^{\circ} \mathrm{C}$ ) increased survival in exposed amphibians (Andre et al. 2008, Bustamante et al. 2010). Amphibians often modify their body temperature behaviorally, including in response to infection (Hutchison \& Dupré 2002), and a recent field study suggests behavioral fever in frogs during $B d$ outbreaks (Richards-Zawacki 2009). Host-specific responses to $B d$ suggest that predictions of population declines that are based on average air temperatures and $B d$ growth in vitro are likely simplistic.

Most experiments challenging post-metamorphic amphibians with $B d$ have not manipulated the hydric environment, providing either facultatively (Lamirande \& Nichols 2002, Berger et al. 2004) or obligately (Carey et al. 2006) wet environments. Although some riparian cloudforest species may experience frequentto-constant contact with water (Lips et al. 2003), the habitats of other adult amphibians exposed to $B d$ vary widely. In addition, pond breeders like boreal toads, may be in contact with water frequently during breeding but thereafter move away from standing water for extended periods (e.g. from weeks to months; Bartelt et al. 2004). Phenological changes in habitat may be linked to changes in individual infection status within a season and over years in long-lived species (Corn 2007, Murray et al. 2009). Experimental studies, however, have just begun to test whether the manifestation of disease with $B d$ infection changes with hydric environment and with prior infection status (Bustamante et al. 2010, Ramsey et al. 2010).

Boreal toads vary regionally in their manifestation of chytridiomycosis with Bd infection (Muths et al. 2003, Pilliod et al. 2010). In this study, we sought to explore how microenvironment and prior exposure interact to affect the severity of chytridiomycosis in boreal toads. First, we tested and distinguished the effects of humid- ity and direct contact with water on disease progression, in order to clarify our earlier findings (Murphy et al. 2009), which were potentially confounded by body mass or population (toads were from distinct clades; Goebel et al. 2009), and to explore how husbandry influences the outcome of $B d$ infection. Second, we tested how a moderate temperature increase, within the optimal range for growth of $B d$, affects toad survivorship after $B d$ infection, and examined thermal selection by toads for evidence of behavioral fever. Third, we tested whether previous exposure influenced subsequent survivability of exposure by comparing the trajectory of infection in previously exposed and $B d$-naïve toads.

\section{MATERIALS AND METHODS}

We obtained 52 yearling boreal toads from the Colorado Division of Wildlife Native Aquatic Species Restoration Facility, offspring from several crosses of adults raised from eggs collected in Pitkin County, Colorado in 2001. During the $35 \mathrm{~d}$ until the first exposure was conducted, toads were housed at the ISU Animal Care Facility in two $100 \mathrm{l}$ aquaria. We provided fresh dechlorinated water and crickets dusted with calcium (ReptoCal) daily. Aquaria were held under full spectrum lighting (Reptisun 5.0) and a 23 to $17^{\circ} \mathrm{C} 12 \mathrm{~h}$ day: $12 \mathrm{~h}$ night cycle, within the range of temperatures experienced by toads in the field (Hossack et al. 2009).

Exposure 1. Effect of humidity and temperature on disease severity. We selected 48 toads for an 8 treatment design that crossed three 2-level factors, each with 6 replicates: pathogen exposure ( $B d$ exposed vs. control), humidity (high vs. low), and temperature (heated vs. ambient). Individuals ranged in weight from 5 to $33 \mathrm{~g}$ (mean 17.9), with no differences by treatment $\left(F_{7,40}=0.2, \mathrm{p}=0.973\right)$.

Toads were housed individually in 81 glass aquaria. Dechlorinated tap water $(75 \mathrm{ml})$ was provided in two $9 \mathrm{~cm}$ diameter glass petri dishes, one at each end of the aquaria (back and front). Aquarium floors were dry. The $\mathrm{pH}(\sim 7.2)$, alkalinity, and total dissolved solids of the water used were within the range measured at boreal toad-breeding sites in NW Wyoming (Hawk 2000). Moreover, the tap water did not compromise $B d$, as we have induced lethal chytridiomycosis in toads exposed in this water in prior experiments (Murphy et al. 2009).

Heated aquaria had a $6 \mathrm{~cm}$ wide thermal strip (CalorIQue) under one end, while ambient aquaria lacked this strip. Temperature treatments (Table 1A) reflected the low to middle range of what a toad in the field could experience during mid-summer daylight

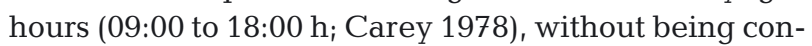
sistently too hot to halt $B d$ growth $\left(\geq 28^{\circ} \mathrm{C}\right.$ for $2 \mathrm{~d}$; Pi- 
Table 1. Mean relative humidity (RH) and temperature (air, water, and Anaxyrus b. boreas dorsum) by treatment during (A) Period 1 (Days 0 to 64) and (B) Period 2 (Days 67 to 179)

\begin{tabular}{|c|c|c|c|c|}
\hline Treatment & $\begin{array}{l}\mathrm{RH}(\% \pm 1 \mathrm{SE}) \\
\text { (min., max.) }\end{array}$ & $\begin{array}{l}\text { Air temp. }\left({ }^{\circ} \mathrm{C} \pm 1 \mathrm{SE}\right) \\
\text { (min., max.) }\end{array}$ & $\begin{array}{l}\text { Water temp. }\left({ }^{\circ} \mathrm{C} \pm 1 \mathrm{SE}\right) \\
\quad \text { (min., max.) }\end{array}$ & $\begin{array}{l}\text { Toad temp. }\left({ }^{\circ} \mathrm{C} \pm 1 \mathrm{SE}\right) \\
\text { (min., max.) }\end{array}$ \\
\hline \multicolumn{3}{|c|}{ (A) Period 1 (post-Exposure 1) } & Front dish & \\
\hline Low RH, ambient & $44 \pm 2 \quad(33,57)$ & $19.5 \pm 0.2 \quad(16.4,23.6)$ & $16.8 \pm 0.3(12.7,17.9)$ & $15.5 \pm 0.1 \quad(11.3,19.9)$ \\
\hline Low RH, heated & $41 \pm 3(27,68)$ & $21.0 \pm 0.4(14.9,27.1)$ & $25.1 \pm 0.7(14.0,31.5)$ & $17.0 \pm 0.3(11,28.8)$ \\
\hline High RH, ambient & $83 \pm 4(50,100)$ & $19.8 \pm 0.2(16.4,24.0)$ & $17.5 \pm 0.1(12.5,20.3)$ & $17.7 \pm 0.1(13.3,20.9)$ \\
\hline High RH, heated & $76 \pm 4 \quad(37,92)$ & $24.0 \pm 0.7(16.0,27.1)$ & $28.0 \pm 0.4(14.7,33.2)$ & $21.9 \pm 0.2(14.1,30.9)$ \\
\hline \multicolumn{3}{|c|}{ (B) Period 2 (post-Exposure 2) } & Center of aquarium floor & \\
\hline Ambient & $41 \pm 3(24,88)$ & $19.6 \pm 0.2(18.3,20.6)$ & $15.6 \pm 0.3(12.1,18.4)$ & $15.0 \pm 0.1(11.7,17.8)$ \\
\hline Heated & $34 \pm 4 \quad(23,83)$ & $21.6 \pm 1.0(19.0,24.8)$ & $18.0 \pm 1.1(11.6,27.3)$ & $17.8 \pm 0.7 \quad(11.4,27.6)$ \\
\hline
\end{tabular}

otrowski et al. 2004). We manipulated humidity using different aquarium lids, using clear plastic sheeting for high humidity and no-see-um mesh (Balson Hercules Group) for low humidity. The humidity treatments (Table 1A) were within the observed range during daylight in montane habitat, with 'low' approximating the median of dry woodlands and 'high' approximating conditions in burrows or closed-canopy habitat near water (P. J. Murphy unpubl. telemetry data).

Drip inoculation: Toads were exposed to $B d$ using a protocol that simulated natural conditions in which toads enter water periodically to rehydrate (Bartelt et al. 2004). Immediately prior to exposure, we swabbed each animal's venter with a polyester swab and sent swabs in $70 \%$ ethanol to Pisces Molecular (Boulder, Colorado, USA) for $B d$ testing via PCR (protocol modified from Annis et al. 2004). Bd isolate JEL \#275 was grown in pure culture on sealed TGhL (tryptone, hydrolysed gelatine, lactose) plates and scraped with a spatula into tryptone broth. For control inoculate, we scraped sterile TGhL plates into tryptone broth. The broth in both cases was treated with $0.2 \mathrm{mg} \mathrm{ml}^{-1}$ penicillin-streptomycin (Hyclone). The average daily $B d$ inoculate $( \pm 1 \mathrm{SE})$ was $5.8 \pm 0.8 \times 10^{5}$ zoospores $\mathrm{ml}^{-1}$, quantified with a hemocytometer. We inoculated toads for $5 \mathrm{~d}$ by holding them with a gloved hand and dripping $1 \mathrm{ml}$ of broth on the venter, with the excess dripping into the water dishes in aquaria. We term this 'drip' inoculation to distinguish it from the 'bath' method (see 'Exposure 2'). Here toads could escape the infective solution, although they tracked some water around the aquaria. Each day we inoculated toads over clean, re-filled dishes. Scans of shed skins (see 'Monitoring') demonstrated that drip inoculation caused infection: 20 of 24 exposed toads had $\geq 1$ shed with $B d$ sporangia within 3 wk of exposure.

Monitoring: We recorded whether toads were in contact with water (in water dish) once or twice daily. Toad temperatures were taken daily with a noncontact infrared thermometer (TTI Instruments) held $\sim 10 \mathrm{~cm}$ from the toad's dorsum (Rowley \& Alford 2007). We recorded water temperatures in dishes every $2 \mathrm{~d}$ in control aquaria using a thermister from an Omega handheld thermometer. Subsequently, we replaced dirty water dishes with clean ones and refilled them, and fed 3 to 5 crickets to each toad. Humidity and air temperatures were logged every $10 \mathrm{~min}$ in control aquaria (2 Onset loggers per treatment combination, rotated weekly). We weighed toads weekly to the nearest $0.1 \mathrm{~g}$, each on sterile KimWipe (KimberlyClark), tared prior to measurement.

Each day, we prepared wet mounts of any shed skin found in each cage. These samples were scanned for $B d$ sporangia for $3 \mathrm{~min}$ at $200 \times$ under a light microscope. Samples were scored, blind to treatment, as negative $(0$, no $B d$ sporangia), positive $(1$, sporangia diffuse), strong positive (1.1, several large clusters), or very strong positive $(1.2$, clusters large, dense, and widespread), with borderline cases confirmed by 2 observers (P.J.M. and S.S.H.). We have successfully used this method to monitor $B d$-infection status in boreal toads (Murphy et al. 2009) as have Berger et al. (2004) and Padgett-Flohr (2008) in other species.

Statistical analysis: We examined temporal trends in $B d$ infection status in four $16 \mathrm{~d}$ periods using infection scores from shed skin. A total of $16 \mathrm{~d}$ was sufficient time to include at least 1 shed per toad per period, and we calculated an average score per period for each toad. We compared infection score by treatment and time period using factorial, repeated measures ANOVA (SAS version 9.1 for this and all subsequent analyses). We tested how toad weight (average change weekly), rate of skin shedding (days skin found/60 total days), time in contact with water (proportion of total observations), and toad temperature (average of total observations) depended on treatment using factorial ANOVA.

Exposure 2. Effects of contact with water, temperature, and prior $B d$ exposure on disease severity. After $64 \mathrm{~d}$ without mortality and what appeared from the microscopic evaluation of the shed skins to be recover- 
ing animals (see Fig. 1, grey line), we swabbed each toad's venter for diagnostic PCR and re-inoculated a subset of them with $B d$ using the bath method of Carey et al. (2006). By following their inoculation and husbandry methods, we sought to determine whether bath inoculation, constant contact with water, or both, were required for $B d$ infection to cause mortality in boreal toads. A second exposure also allowed us to assess whether prior exposure to $B d$ affects the progression of disease in re-exposed toads.

Boreal toads in Exposure 2 were distributed into 9 treatment groups (Table 2), 8 of which were a combination of three 2-level treatments $(2 \times 2 \times 2)$ that crossed an animal's Exposure 1 history ( $B d$-naïve or $B d$-experienced) with a second inoculation treatment ( $B d$ bath or control) and a contact with water treatment (obligate vs. facultative). The ninth treatment group matched the fourth group ( $B d$-naïve $+B d$ bath + facultative contact with water) except that after inoculation toads were placed in aquaria with a heat strip at one end. By comparing Groups 9 and 4, we tested the effect of moderate heat on disease progression. Contact with water was manipulated by providing 2 platforms (inverted glass petri plates, $0.8 \mathrm{~cm}$ high, $9 \mathrm{~cm}$ diameter) in each aquarium designated 'facultative'. Toads could thus select a drier environment in these aquaria, while toads in the 'obligate' treatment without platforms always had at least their hind feet in water. A total of 51 toads were involved: 47 from Exposure 1 (1 was excluded due to a husbandry error) plus $4 \mathrm{Bd}$ naïve animals that had been raised throughout in 1 large aquarium under ambient temperature, low humidity conditions (as in Table 1A, row 1). From within each pre-exposure category (naïve or previously exposed), toads were randomly drawn and assigned to treatment groups (Group 1 to 4,9 or 5 to 8, respectively, Table 2). We stratified random assignments according to 2 conditions in order of priority: (1) such that initial toad mass did not differ among groups $\left(F_{8,42}=0.2, \mathrm{p}=0.993\right)$, and (2) such that toads from each heat and humidity combination in Exposure 1 were proportionately represented among Exposure 2 groups.

Bath inoculation: Toads were exposed to $B d$ using the protocol of Carey et al. (2006). As above, we swabbed toads' venter pre-exposure and had swabs tested for $B d$ by diagnostic PCR. We inoculated toads using a 'bath' for $3 \mathrm{~d}$ (Days 64 to 66 after Exposure 1 began). $B d$ and control inoculates were prepared daily as in Exposure 1. $B d$ inoculate averaged $1.2 \pm 0.2 \times$ $10^{6}$ zoospores $\mathrm{ml}^{-1}$. We dripped $1.5 \mathrm{ml}$ of inoculate on each toads' venter over small, inoculation chambers (709 ml; Glad Products) containing $40 \mathrm{ml}$ of $20 \%$ Holtfreter's solution. Toads could not escape the inoculate bath, which was $\sim 3$ to $4 \mathrm{~mm}$ deep across the bottom (ensuring coverage for $24 \mathrm{~h}$ ). The mean concentration of $B d$ inoculate within chambers was $4.4 \pm 0.8 \times$ $10^{4}$ zoospores $\mathrm{ml}^{-1}$, and the cumulative inoculate per toad was $\sim 5.4 \times 10^{6}$ zoospores $\mathrm{ml}^{-1}$. Each day before inoculation, we rinsed and re-filled chambers with fresh Holtfreter's solution.

Monitoring: After the $3 \mathrm{~d}$ bath inoculation period, toads were transferred to clean 81 glass aquaria identical to those in Exposure 1, but filled with $350 \mathrm{ml}$ of $20 \%$ Holtfreter's solution (ensuring complete floor coverage $\sim 4$ to $5 \mathrm{~mm}$ deep between water changes) and covered with mesh lids. Unlike in Murphy et al. (2009), the toads here were heavier (Day 64 mean: $18.0 \pm 1.0 \mathrm{~g}$ ) and could not climb walls to escape wet aquarium bottoms. Hence, contact with water was obligate in treatments without platforms (although toads would occasionally stand on their hind feet against walls), and facultative when they were available. Even with platforms, the default conditions were wetter in Period 2 (Days 67 to 179) than Period 1 (Days 0 to 64): during Period 2 toads had to climb onto platforms to escape water, while during Period 1 the floors of the aquaria were nearly dry.

Once or twice daily we noted the toad's position in the aquaria (back $=-1$, center $=0$, or front

an 'Facultative' aquaria, toads could climb on platforms to dry off; in 'Obligate' aquaria, no platforms were available. ${ }^{\mathrm{b}}$ See Table $1 \mathrm{~B}$ 
[over heat strip where present] = 1) and whether it was in contact with water (on the floor) or not (on a platform, if available). We measured the dorsal surface temperature of each toad using a non-contact infrared thermometer 3 to 5 times per week at times ranging from mid-morning to early evening. Toads were weighed weekly as after Exposure 1.

We changed the Holtfreter's solution and platforms (where present) 3 times per week, at which time wet mounts of shed skin were scored for $B d$ as after Exposure 1. Prior to water changes on Days 84, 118, and 179 , we filtered $\sim 200 \mathrm{ml}$ of liquid from 17 aquaria. $B d$ loads were quantified with quantitative PCR (qPCR) according to Kirshtein et al. (2007). Sampling was limited by processing costs, although we selected aquaria randomly from treatment groups with surviving toads at sampling time without repeating aquaria. After water changes, toads were fed 3 to 5 crickets (dusted with ReptoCal).

Any toad that appeared severely lethargic or lacked a righting reflex was euthanized in MS-222 (2 to $3 \mathrm{~g}$ $\left.\mathrm{l}^{-1}\right)$. Upon death, we dissected and scored ventral skin for $B d$ sporangia as above, and preserved skin and foot samples in $70 \%$ ethanol. We also conducted a gross necropsy on each toad, noting any abnormalities. The Eposure 2 study period ended on Day 179 (115 d after bath inoculation began), 3 to 5 times the period necessary for $100 \%$ mortality at equivalent $B d$ dosage in Carey et al. (2006). We euthanized all survivors, examined skin wet mounts and internal organs, and collected tissues for $B d$ testing by diagnostic PCR.

Statistical analysis: We used proportional hazards regression to compare the effects of bath $B d$ exposure (Days 64 to 66), prior Bd exposure (drip, Days 0 to 4), and contact with water on toad survival. Models including the $100 \%$ surviving controls (all censored) would not converge. Hence, we compared toad survival based on $3 B d$-exposure groups (drip only, bath only, and drip + bath), contact with water (obligate vs. facultative), and their interaction. We included toad mass as a covariate to help control for its effect on survival time (Carey et al. 2006) and any significant timedependent covariates (Allison 1995). We used a logrank test to compare survival in heated aquaria with platforms to that in comparable unheated aquaria.

We tested how toad weight (average weekly change), rate of skin shedding (days skin found/112 total days), time dry on platforms (proportion of total observations), body temperature (average), and resting position (average) depended on treatment using factorial ANOVA. We used $t$-tests (heterogeneous variance) to compare these responses in Groups 9 and 4. We also used ANOVA to compare filtered $B d$ zoospore concentration in aquaria by date, treatment, and their interaction.

\section{RESULTS}

\section{Exposure 1. Effects of humidity and temperature on disease severity}

No toads died after the first exposure, but we detected differences in the degree of infection, growth, and skin shedding by treatment. $B d$ infection scores were lower in toads from heated than ambient aquaria, did not differ by aquarium humidity, and no interactive effects were evident (Table 3, Fig. 1). The mean score across treatments declined significantly during the last sampling period (Fig. 1, grey line). Based on diagnostic PCR of skin swabs, 0 toads were $B d$ positive at the start of Exposure 1, and 0 controls and 5 of 24 exposed were positive on Day 64 (4 ambient, 1 heated).

The $B d$ exposure and temperature treatments interacted in their effects on toad weight, although the main effect of neither was significant (Table 4). Warmer temperature decreased weight gain in control toads, but this effect was reversed in toads exposed to $B d$ (Fig. 2A). The humidity treatment did not affect weight, and no other interactions were observed. Skin shedding showed a similar interactive response to $B d$ exposure and temperature (Table 4), with the highest rate in exposed ambient aquaria, an intermediate rate in heated aquaria, and the lowest rate in control ambient aquaria (Fig. 2B). Overall, skin sheds were observed more frequently in toads exposed to $B d$ (mean $\mathrm{d}^{-1} \pm 1$ SE: $\left.0.14 \pm 0.01\right)$ than in controls $(0.08 \pm$ $0.01)$ and less frequently in more humid (0.08 \pm 0.01$)$ than drier aquaria $(0.14 \pm 0.01)$.

Mean toad temperatures were 2 to $4^{\circ} \mathrm{C}$ lower than air temperatures but tracked the pattern in air temperature by treatment (Table 1A). Both heating and humidity treatments altered toad temperature, and interacted significantly, but there were no effects of $B d$ exposure on toad temperature nor any other interac-

Table 3. Anaxyrus b. boreas. Repeated measures, factorial ANOVA of $B d$ infection scores over four $16 \mathrm{~d}$ periods following Exposure 1. For each period, a subject's score was the average of the readings on skin shed during the previous $16 \mathrm{~d}$. Factors were relative humidity ( $\mathrm{RH}_{\text {; low }}$ or high) and temperature ( $T_{\text {; }}$ ambient or heated; Table 2). Analysis includes only exposed toads ( $\mathrm{n}=24$; all scores were zero for the 24 controls). Significant effects in bold

\begin{tabular}{|lcrc|}
\hline Factor & df & \multicolumn{1}{c|}{$F$} & $\mathrm{p}$ \\
\hline $\mathrm{RH}$ & 1,19 & 0.1 & 0.833 \\
$\mathrm{~T}$ & 1,19 & 13.5 & $\mathbf{0 . 0 0 2}$ \\
$\mathrm{RH} \times \mathrm{T}$ & 1,19 & 0.1 & 0.747 \\
Period & 3,37 & 4.9 & $\mathbf{0 . 0 0 6}$ \\
RH $\times$ Period & 3,37 & 2.1 & 0.124 \\
$\mathrm{~T} \times$ Period & 3,37 & 1.3 & 0.300 \\
RH $\times$ T $\times$ Period & 3,37 & 1.7 & 0.181 \\
\hline
\end{tabular}




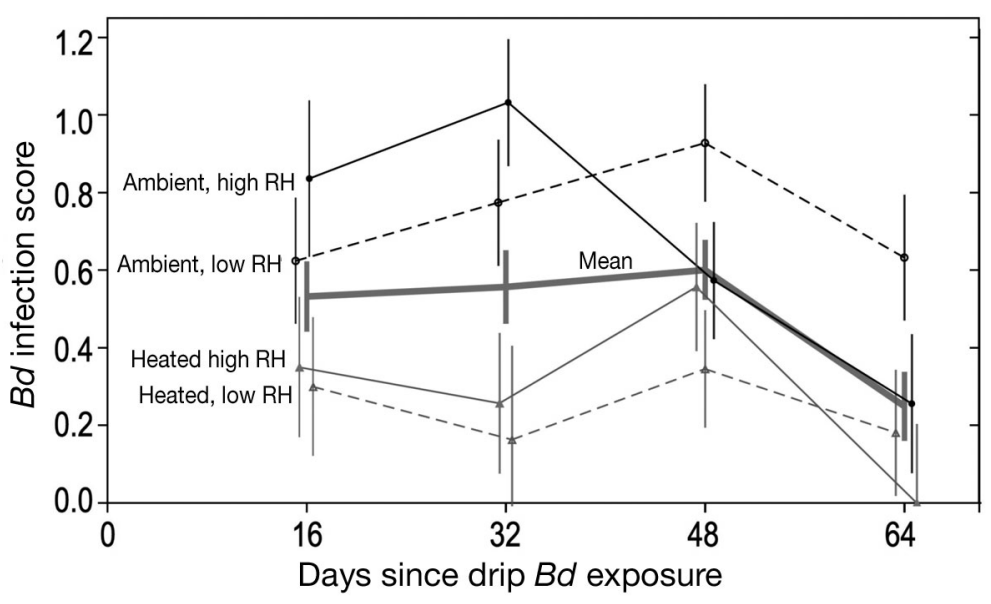

Fig. 1. Anaxyrus b. boreas. Infection scores based on shed skin in Bd-exposed toads $(\mathrm{n}=24)$ by microenvironment treatment during Period 1 (Days 0 to 64). Each point represents the treatment mean $( \pm 1 \mathrm{SE})$ based on the average infection scores of 6 toads for the previous $16 \mathrm{~d}$. Thick grey line connects the means across treatments $( \pm 1 \mathrm{SE})$ by time period. Mean scores differed by temperature and time but not humidity, and there were no interactions (Table 3). Table 1A gives the means and ranges of the temperature and humidity treatments. $\mathrm{RH}$ : relative humidity

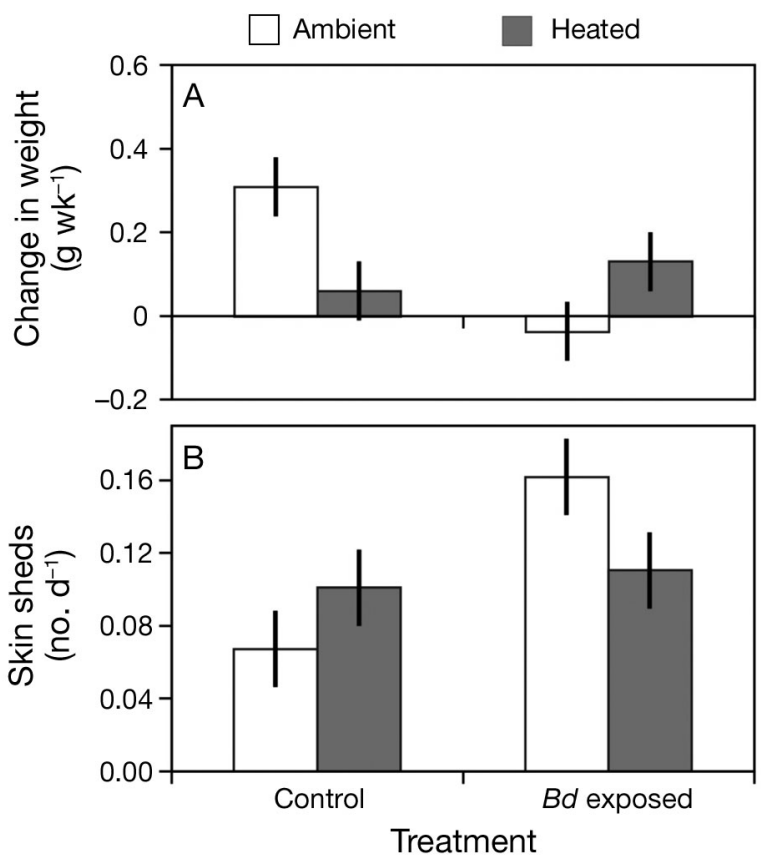

Fig. 2. Anaxyrus b. boreas. (A) Weight change and (B) rate of skin shedding in toads during Period 1 (Days 0 to 64) by pathogen and temperature treatments (mean $\pm 1 \mathrm{SE}, \mathrm{n}=12$, humidity treatments pooled). Pathogen exposure and temperature interacted to affect growth and skin shedding (Table 4). Table 1A gives the means and ranges of the temperature treatments

tions (Table 4). Bd exposure and temperature did not change the tendency of toads to select wet sites, yet toads in high humidity aquaria spent less time in water dishes than those in drier aquaria (Table 4).

\section{Exposure 2. Effects of contact with water, temperature, and prior $B d$ exposure on disease severity}

Continuous contact with water accelerated the onset of lethal chytridiomycosis in boreal toads, but prior exposure to $B d$ and a moderate increase in aquarium temperature slowed the onset of lethal disease. All 10 unexposed toads survived (Fig. 3A, Groups 1 and 2), but only 7 of 41 toads exposed to $B d$ survived through to Day 179. Exposed survivors were all from aquaria with platforms (Fig. 3A, Groups 6, 8 and 9). By PCR, all exposed toads were strongly $B d$ positive at death or on Day 179, and 4 of 10 controls were weakly positive. The PCRpositive controls may have resulted from contamination during shipment (when several vial lids popped) or PCR analysis; scores of skin wet mounts showed no positive controls (Fig. 3B, Groups 1 and 2).

The proportional hazards regression showed that toad survival depended on $B d$ exposure treatment and contact with water (Table 5A). Although there was no main effect of contact with water, an interactive effect with $B d$ exposure arose because the availability of platforms had a stronger protective effect in twice-exposed toads (drip + bath, Fig. 3A, Group 7 vs. 8) than in toads exposed only by bath (Group 3 vs. Group 4) or drip (Group 5 vs. Group 6). When compared across exposure groups (Table 5B), the ability to dry off periodically increased mean survival time nearly 3-fold, from 18 to $48 \mathrm{~d}$. Log-rank tests among exposure treatments also showed that bath inoculation reduced survival time compared to exposure via drip and drip + bath.

Toads usually began to die within a treatment group when their average $B d$ infection score was $\geq 0.8$ for more than one $16 \mathrm{~d}$ period (Fig. 3B). In toads exposed by drip only, infection scores increased slowly and did not exceed this level until the fourth period (Day 128); at this time, scores peaked in aquaria without platforms (Group 5) and increased more slowly in aquaria with platforms, in which several toads survived longer (Group 6). In the double-exposed toads (drip + bath), scores quickly peaked in those in obligate contact with water (Group 7) but fluctuated at an intermediate level in those in facultative contact with water (Group 8).

A moderate increase in aquarium temperature (Table 1B) strongly protected toads against lethal chytridiomycosis (Fig. 3A, Table 5B). Toads in heated aquaria, however, retained high levels of $B d$ infection (Fig. 3B, Group 9).

Similar to after Exposure 1, toad weight and skinshedding were affected by Bd exposure during Period 2. 
Table 4. Anaxyrus b. boreas. Factorial ANOVA of 4 responses measured on 48 toads during Period 1 (Days 0 to 64): weight change, rate of skin shedding, body temperature, and time in water. Factors were $B d$ exposure (Exp; $B d$ or control), relative humidity $\left(\mathrm{RH}_{i}\right.$ low or high) and temperature $\left(\mathrm{T}_{\text {; }}\right.$ ambient or heated; Table 2$)$. Significant effects in bold

\begin{tabular}{|c|c|c|c|c|c|c|c|c|c|}
\hline \multirow[t]{2}{*}{ Factor } & \multirow[t]{2}{*}{ df } & \multicolumn{2}{|c|}{ Weight change } & \multicolumn{2}{|c|}{ Skin shedding } & \multicolumn{2}{|c|}{ Toad temperature } & \multicolumn{2}{|c|}{ Time in water } \\
\hline & & $F$ & $\mathrm{p}$ & $F$ & $\mathrm{p}$ & $F$ & $\mathrm{p}$ & $F$ & $\mathrm{p}$ \\
\hline Exp & 1 & 1.3 & 0.268 & 6.1 & 0.018 & 0.3 & 0.581 & 0.7 & 0.423 \\
\hline RH & 1 & 1.7 & 0.207 & 6.5 & 0.015 & 398.8 & $<0.001$ & 5.2 & 0.028 \\
\hline $\mathrm{T}$ & 1 & 1.9 & 0.178 & 0.2 & 0.677 & 254.1 & $<0.001$ & 0.4 & 0.512 \\
\hline $\operatorname{Exp} \times \mathrm{RH}$ & 1 & 0.1 & 0.830 & 0.6 & 0.428 & 0.0 & 0.967 & 0.3 & 0.576 \\
\hline $\operatorname{Exp} \times \mathrm{T}$ & 1 & 9.3 & 0.004 & 4.1 & 0.050 & 1.0 & 0.328 & 0.0 & 0.865 \\
\hline $\mathrm{RH} \times \mathrm{T}$ & 1 & 0.6 & 0.442 & 1.8 & 0.190 & 63.3 & $<0.001$ & 0.4 & 0.512 \\
\hline $\operatorname{Exp} \times \mathrm{RH} \times \mathrm{T}$ & 1 & 0.0 & 0.854 & 0.3 & 0.571 & 0.3 & 0.606 & 0.7 & 0.396 \\
\hline Error & 40 & & & & & & & & \\
\hline
\end{tabular}
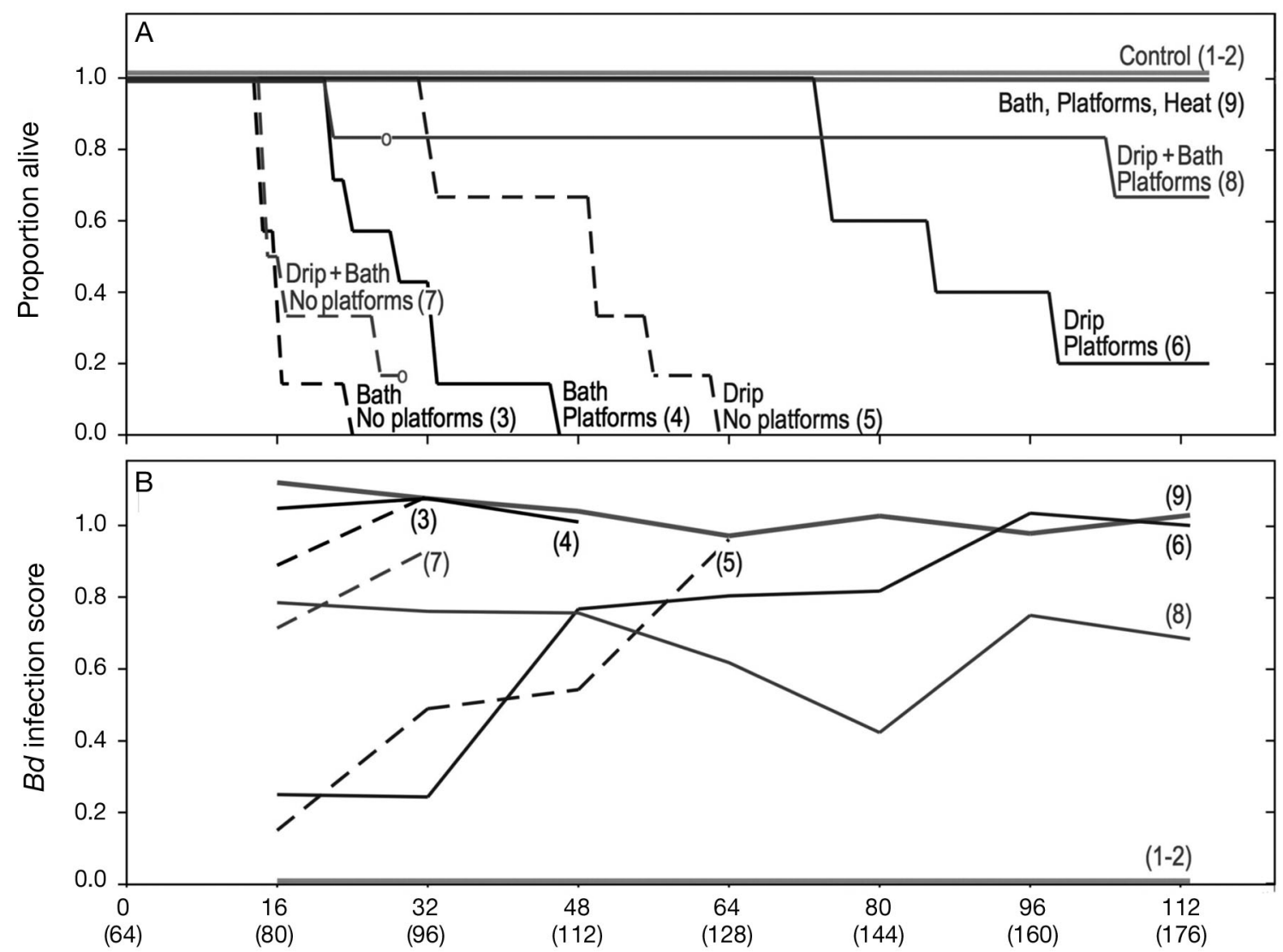

Days since $B d$ bath (and drip) exposure

Fig. 3. Anaxyrus b. boreas. (A) Survivorship and (B) Bd infection score in toads during Period 2 (post-Exposure 2, Days 67 to 179 ). Numbers in parentheses correspond to treatment groups (Table 2). Toads were exposed to Bd by drip on Days 0 to 4 , by bath on Days 64 to 66, by both methods at their respective times (drip + bath), or remained unexposed (control). Half of each exposure combination were in obligate contact with water (dashed lines), while the other half were in facultative contact (solid lines). In (B), lines link points that are averages based on living toads in that treatment during the previous $16 \mathrm{~d}$ (SEs omitted for clarity). Circles (o) in (A) indicate censored individuals $(\mathrm{n}=3$ ) due to a husbandry error on Day 93. Proportional hazards analysis showed effects on survivorship of exposure type, contact with water, and temperature (Table 5A)

Prior $B d$ exposure by itself did not affect weight change, while bath exposure increased weight loss (Table 6). The exposure treatments had an interactive effect on weight change, such that toads exposed twice to $B d$ (drip + bath) lost less weight than those exposed via bath alone (Fig. 4A). A similar pattern was observed with respect to the rate at which shed skin was detected, with no effect of drip exposure, an 
Table 5. Anaxyrus b. boreas. Survival analysis of boreal toads during Period 2 (Days 67 to 179). (A) Proportional hazards regression comparing survival by $B d$ exposure treatment (Exp), contact with water $\left(\mathrm{CwH}_{2} \mathrm{O}\right)$, and their interaction $(\mathrm{n}=37$; excludes $\mathrm{Groups} 1$, 2 [controls] and 9, Table 2). Average toad weight (Wt) and a time-dependent covariate of average weight (Wt TD) were included to improve fit and control for nonproportional hazards. (B) Log-rank tests comparing survival of specific treatment groups: (1) by $B d$ exposure treatment, (2) by contact with water, and (3) in moderately heated versus ambient aquaria. Significant effects in bold

\begin{tabular}{|c|c|c|c|c|c|c|c|c|c|c|}
\hline $\begin{array}{l}\text { (A) Proportion } \\
\text { Variable }\end{array}$ & $\begin{array}{l}\text { haz } \\
\text { df }\end{array}$ & $\begin{array}{l}\text { reg } \\
\chi^{2}\end{array}$ & $\begin{array}{r}\text { sion } \\
p\end{array}$ & \multicolumn{2}{|c|}{$\begin{array}{l}\text { (B) Log-rank tests } \\
\text { Contrast }\end{array}$} & Groups compared & df & $\chi^{2}$ & $\mathrm{p}$ & $\mathrm{n}$ \\
\hline $\operatorname{Exp}$ & 1 & 9.1 & 0.003 & (1) & Bath vs. Drip & 3,4 vs. 5,6 & 1 & 20.4 & $<0.001$ & 25 \\
\hline $\mathrm{CwH}_{2} \mathrm{O}$ & 1 & 0.6 & 0.450 & & Bath vs. Drip + Bath & 3,4 vs. 7,8 & 1 & 4.1 & 0.044 & 26 \\
\hline $\operatorname{Exp} \times \mathrm{CwH}_{2} \mathrm{O}$ & 1 & 3.9 & 0.048 & & Drip vs. Drip + Bath & 5,6 vs. 7,8 & 1 & 0.0 & 0.976 & 23 \\
\hline $\mathrm{Wt}$ & 1 & 1.5 & 0.223 & $(2)$ & $\mathrm{CwH}_{2} \mathrm{O}$ & $3,5,7$ vs. $4,6,8$ & 1 & 4.2 & 0.040 & 37 \\
\hline Wt TD & 1 & 3.4 & 0.067 & (3) & Moderate heat & 4 vs. 9 & 1 & 8.8 & 0.003 & 11 \\
\hline
\end{tabular}

Table 6. Anaxyrus b. boreas. Factorial ANOVA of 3 responses measured on 47 toads during Period 2 (Days 67 to 179): weight change, rate of skin shedding, and time dry (on platforms). All analyses exclude Group 9. Analysis of time dry only includes toads with platforms available. Factors were Exposure 1 (Exp1; $B d$ drip or control), Exposure 2 (Exp2; Bd bath or control), and contact with water $\left(\mathrm{CwH}_{2} \mathrm{O}\right.$; obligate or facultative). Significant effects in bold

\begin{tabular}{|c|c|c|c|c|c|c|c|c|c|}
\hline \multirow{2}{*}{ Source } & \multirow[b]{2}{*}{ df } & \multirow{2}{*}{$\begin{array}{c}\text { Weight change } \\
F\end{array}$} & \multirow{2}{*}{$\overline{\mathrm{p}}$} & \multicolumn{3}{|c|}{ Skin shedding } & \multirow{2}{*}{$\mathrm{df}$} & \multirow{2}{*}{$\begin{array}{l}\text { Time dry } \\
\quad F\end{array}$} & \multirow[b]{2}{*}{$\mathrm{p}$} \\
\hline & & & & $\mathrm{df}$ & $F$ & $\mathrm{p}$ & & & \\
\hline Exp1 & 1 & 0.1 & 0.737 & 1 & 2.8 & 0.103 & 1 & 1.6 & 0.219 \\
\hline Exp2 & 1 & 15.1 & 0.000 & 1 & 7.4 & 0.010 & 1 & 15.3 & 0.001 \\
\hline $\operatorname{Exp} 1 \times \operatorname{Exp} 2$ & 1 & 10.5 & 0.002 & 1 & 3.9 & 0.056 & 1 & 5.8 & 0.027 \\
\hline $\mathrm{CwH}_{2} \mathrm{O}$ & 1 & 0.6 & 0.432 & 1 & 5.5 & 0.024 & & & \\
\hline $\operatorname{Exp} 1 \times \mathrm{CwH}_{2} \mathrm{O}$ & 1 & 1.1 & 0.308 & 1 & 1.5 & 0.234 & & & \\
\hline $\operatorname{Exp} 2 \times \mathrm{CwH}_{2} \mathrm{O}$ & 1 & 0.0 & 0.979 & 1 & 2.9 & 0.095 & & & \\
\hline $\operatorname{Exp} 1 \times \operatorname{Exp} 2 \times \mathrm{CwH}_{2} \mathrm{O}$ & 1 & 0.0 & 0.976 & 1 & 0.1 & 0.752 & & & \\
\hline Error & 39 & & & 39 & & & 19 & & \\
\hline
\end{tabular}

increase with bath exposure, and an interactive effect between them (Table 6, Fig. 4B). The frequency of detecting skin sheds was higher in toads in obligate contact with water compared to facultative contact (Table 6). When Groups 9 and 4 were compared, toads in heated aquaria lost less weight ( $t$-test, $t=3.6, \mathrm{df}=9$, $\mathrm{p}=0.006)$ and shed skin was detected less frequently $(t=1.5, \mathrm{p}=0.162)$.

The tendency to select dry sites differed by exposure treatment following Exposure 2. Prior Bd exposure did not affect the tendency to use platforms, but exposure via bath increased their use (Table 6). Again the treatments interacted such that twice-exposed toads used platforms less often than those exposed via bath alone (Fig. 4C). In unheated aquaria, the mean body temperature did not differ by treatment $\left(F_{1,37} \leq 2.2, \mathrm{p} \geq 0.143\right)$, nor did the mean resting position within aquaria $\left(F_{1,39} \leq 1.6, \mathrm{p} \geq 0.215\right)$. When resting sites in Groups 9 and 4 were compared, the mean in heated aquaria was shifted towards the heat strip $\left(t_{9}=2.2, \mathrm{p}=0.060\right)$.

$B d$ zoospore concentrations in water (log-transformed) in a subset ( $\mathrm{n}=17$ ) of $B d$-exposed aquaria did not differ by exposure type, heat, or date $\left(F_{1,16} \leq 0.3, \mathrm{p} \geq\right.$ 0.331 ). However, zoospore loads differed in the contact with water treatment (unheated aquaria only, $F_{1,13}=$ 12.3, p = 0.004): zoospore loads (back-transformed means) were higher in aquaria without platforms $\left(450 \mathrm{ml}^{-1}\right)$ than in those with platforms $\left(16 \mathrm{ml}^{-1}\right)$.

\section{DISCUSSION}

\section{Periodic drying and moderate warming decrease the severity of infection}

We found that temperature and hydric environment significantly affected disease severity and the outcome of $B d$ infection in boreal toads, extending earlier experimental work on this species by Carey et al. (2006) that demonstrated the effects of $B d$ dose, duration of exposure, and body size on survival time. Toads that could warm themselves moderately, from 15 to $18^{\circ} \mathrm{C}$, survived despite heavy $B d$ infections. Infected toads that could dry off periodically either survived $(179 \mathrm{~d})$, or survived longer than those that could not escape wet environments.

\section{Effects of temperature}

Exposure to high temperatures $\left(37^{\circ} \mathrm{C}\right)$ can kill $B d$ in experimentally infected frogs (Woodhams et al. 2003), 

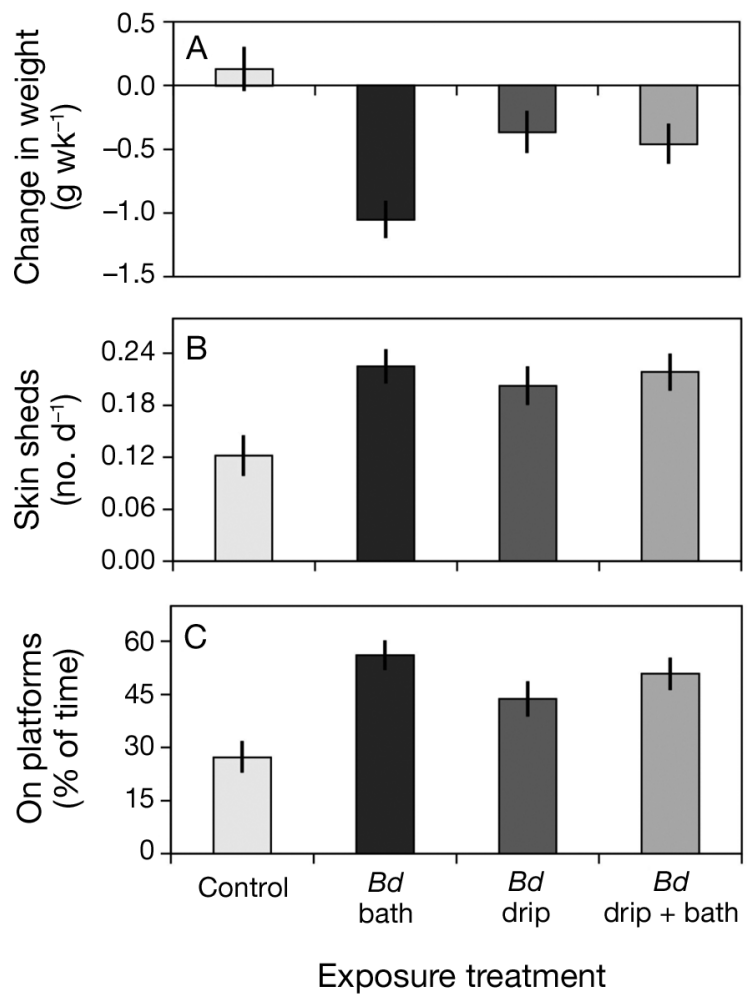

Fig. 4. Anaxyrus b. boreas. (A) Weight change, (B) skin shedding, and (C) use of platforms in toads in ambient aquaria by exposure treatment during Period 2 (Days 67 to 179). Means $( \pm 1 \mathrm{SE})$ in (A) and (B) pool data from aquaria with and without platforms ( $\mathrm{n}=10$ to 14 ), while those in $(\mathrm{C})$ are from aquaria with platforms only ( $\mathrm{n}=5$ to 7 ). For all 3 responses, Exposures 1 and 2 interacted, meaning that the effects of drip + bath exposure on toads were non-additive (Table 6)

but we found that a moderate increase in average toad temperature decreased infection levels (Fig. 1) and increased survival following exposure (Fig. 3A, Group 9 vs. Group 4). Our finding is consistent with the survival benefit of moderate heating observed in 2 recent infection studies (Andre et al. 2008, Bustamante et al. 2010). Interestingly, after Exposure 2, heating did not decrease infection as measured by $B d$ sporangia in skin (Fig. 3B, Group 9 vs. Group 4), suggesting that the toads in heated aquaria did not substantially reduce the infection sustained during bath inoculation. The mean dorsal temperature of toads in heated aquaria (Table 1) was well within the growth optima of $B d$ in pure culture (Piotrowski et al. 2004), and only occasionally were temperatures achieved that may hinder $B d$ growth (maxima 27.6 to $30.6^{\circ} \mathrm{C}$ ). At these temperatures, decreased toad mortality is more likely due to greater effectiveness of the amphibian immune response to $B d$ (sensu Matutte et al. 2000) than the reduced growth rate of $B d$. In severely infected toads post-Exposure 2, this increase in resistance had a behavioral component as toads shifted their resting position towards heat strips, suggesting behavioral fever (Kluger 1978) to combat Bd infection.

Providing moderate heat also decreased secondary effects of $B d$ infection. Exposed toads in heated aquaria gained less weight than unexposed controls at ambient temperature following Exposure 1, suggesting an increase in metabolism without a corresponding increase in available food. But these toads did not lose weight as did the exposed toads in unheated aquaria (Fig. 2A). Likewise, the rate at which shed skin was observed among exposed toads was lower in heated than ambient aquaria (Fig. 2B). Trends were similar following Exposure 2. Andre et al. (2008) also noted persistent yet less severe effects of disease in infected Rana muscosa housed at $22^{\circ} \mathrm{C}$ compared to those housed at $17^{\circ} \mathrm{C}$.

\section{Effects of contact with water}

Carey et al. (2006) reported on $B d$ infection trials with boreal toads in constant contact with water and suggested that infected toads would survive longer when given the chance to dry off periodically. We confirmed this hypothesis, finding that the availability of dry sites increased mean survival time from 18 to $48 \mathrm{~d}$ in toads exposed to $10^{6}$ zoospores at $15^{\circ} \mathrm{C}$. Our findings are consistent with Bustamante et al. (2010), who observed longer survival in infected golden frogs with access to dry sites than those without such access.

Contact with water increased the zoospore load and made the reinfection process more efficient, raising the chances that an infection reached a lethal threshold (sensu Carey et al. 2006). As measured by qPCR on aquariim water, continuously wet toads experienced $\sim 30 \times$ higher $B d$ zoospore doses prior to water changes than did those with platforms (450 vs. $16 \mathrm{ml}^{-1}$, respectively). Infection subsided during Period 1 (Fig. 1) but increased during Period 2 even in toads that were not re-inoculated with $B d$ (Fig. 3, Groups 5 and 6). Infected skin was more likely to fall in water during Period 2 (wet aquarium floors) than Period 1 (water only in dishes). Also, we changed water daily during Period 1 but only every 2 to 3 d during Period 2 (as in Carey et al. 2006), allowing more time for zoospore production from the toad and shed skin.

As skin is compromised with $B d$ infection, toads in contact with water that is hypotonic to blood plasma may be less able to maintain electrolyte concentrations. Marcum et al. (2010) found marginally lower mean osmolalities in $B d$-exposed boreal toads in continuous contact with water than in those in facultative contact. Reduced epidermal function and electrolyte loss, by hindering the conduction of action potentials and cardiac function, appears to be the proximate 
cause of mortality in severe chytridiomycosis (Voyles et al. 2009).

Toads in obligate contact with water may have also suffered more stress than those with platforms available, suppressing their immune response. Although we cannot rule out this possibility, the controls in obligate versus facultative contact with water showed no difference in survival or weight change. In both groups, we observed $100 \%$ survival and a mean weight increase of $0.1 \mathrm{~g} \mathrm{wk}^{-1}$. Moreover, platforms were not fully protective against lethal disease (Fig. 3A, Groups 4 and 6), indicating that the inoculation method, in addition to contact with water, influenced the outcome of infection. Bath inoculation likely resulted in an infection that covered a greater proportion of the skin than inoculation with dry refuges. A more severe infection may overwhelm any immune response, even if the animal can dry off post-inoculation.

Higher aquarium humidity did not significantly increase the severity of $B d$ infection (Fig. 1) unlike the $29 \%$ increase observed by Murphy et al. (2009). This earlier study used a more extreme humidity treatment (mean $93 \%$ vs. 76 to $83 \%$ here) and smaller toadlets (mean weight $0.5 \mathrm{~g}$ ) that may have been more sensitive to the effect of humidity on infection. The lack of an effect of humidity could also be because the sheeting used to alter humidity slightly increased average temperature, perhaps boosting the immune response to $B d$ (see 'Effects of temperature' above).

\section{Prior exposure to $B d$ decreases the severity of infection}

Prior exposure to $B d$ halted or slowed the onset of severe chytridiomycosis, but only when toads could select dry sites. When exposed to $\sim 10^{6}$ zoospores and platforms were available, toads previously exposed to $B d$ lived nearly 3 times longer and had lower infection scores than did $B d$-naïve animals (Fig. 3, Group 4 vs. 8). Secondary effects of infection (weight loss and a tendency to select dry sites) were also smaller in $B d$ experienced than $B d$-naïve toads (Fig. $4 \mathrm{~A}, \mathrm{C}$ ). Increased survival after prior exposure suggests the possibility of acquired immunity to this pathogen, although other responses, such as higher production of hydrophobic molecules combating infection (Woodhams et al. 2006, Rollins-Smith et al. 2009), cannot be excluded.

A recent infection study on Xenopus laevis found that both innate and acquired immunity are involved in the resistance to lethal $B d$ infection (Ramsey et al. 2010). Rollins-Smith et al. (2009) suggest that, mechanistically, the potential for adaptive immunity in Anaxyrus (Bufo) would be similar to that of Xenopus.
Findings by Woodhams et al. (2007) also indicated changes in the components of the cellular immune system in response to $B d$ infection. However, in a highly $B d$-susceptible tropical species, Rosenblum et al. (2009) found no increase in the expression of genes associated with immunity in infected compared to control animals. Unpublished work on boreal toads carried out in the laboratory of $\mathrm{C}$. Carey had findings similar to our own, i.e. increased resistance to $B d$ with prior exposure, but only when dry microenvironments were available (Richmond et al. 2009). As noted above, contact with water likely enhances the effective dose of $B d$, thereby reducing the effectiveness of any immune response. Increased time in water may also interfere with signaling pathways that mobilize acquired immunity (e.g. by Langerhans cells; Richmond et al. 2009) or drive a stress response that interferes with immune function.

\section{From the laboratory to the field: factors promoting endemic infection}

Our findings, and those of Andre et al. (2008) and Bustamante et al. (2010), suggest caution when making predictions about the effects of $B d$ on amphibians in the field based on its growth in vitro (i.e. the 'chytrid thermal optimum hypothesis' sensu Pounds et al. 2006). We found that a moderate increase in temperature within the optimal growth range of $B d$ did not eliminate infection but altered its outcome. Moderate temperature changes may affect the host response to $B d$ in a species-specific manner, which warrants tests with more species (per Carey et al. 1999).

Our study also suggests how boreal toads, a semiaquatic species that moves between wet and dry microenvironments, feeding, basking, and resting (Hammerson 1999), may act behaviorally to reduce their level of infection. When available, we found that $B d$-infected toads tended to select dryer sites (Fig. $4 \mathrm{C}$ ) and warmer sites within aquaria, and these behaviors were associated with longer survival. Infected toads are likely to respond similarly in the field, as suggested by increases in mean temperature observed in golden frogs during a $B d$ epidemic compared to pre-epidemic means (Richards-Zawacki 2009).

Survival of initial $B d$ infection also means individuals may clear infections and become reinfected (Corn 2007). If, as our findings suggest, previously exposed toads combat $B d$ infection more effectively, these individuals may serve as $B d$ reservoirs and vectors, reinfecting others at spring breeding aggregations. In the absence of overwintering tadpoles or a non-amphibian reservoir, $B d$ persistence is more likely if individuals carry low-level infections (Briggs et al. 2010). More- 
over, the high fungal loads that led to lethal infections in our aquaria, and might drive density-dependent disease outbreaks in natural populations (sensu Briggs et al. 2010), may be highly unusual. In 4 active boreal toad-breeding sites with $B d$-positive adults (2 in Wyoming and Colorado), 24 of 36 water samples were $B d$-negative by $\mathrm{qPCR}$, and the highest zoospore load observed during breeding was $0.2 \mathrm{ml}^{-1}$ (authors' unpubl. data), $\sim 80$ to 2000 times below loads in our $B d$-exposed aquaria. Hence, high prevalence (Murphy et al. 2009) and endemic persistence of $B d$ in boreal toads (Pilliod et al. 2010) is not surprising. In Panama, after epidemic decline of riparian amphibians, high $B d$ prevalence has been observed in pond-breeding species, and may also arise from their ability to act as $B d$ reservoirs and vectors (Brem \& Lips 2008).

Acknowledgements. We thank M. Kelemete, R. Marcum, D. Baumer, and A. Wilson for help with animal husbandry. E. Davinroy and the Colorado Division of Wildlife provided animals from the John W. Mumma Native Aquatic Species Restoration Facility. This project was funded by USGS ParkOriented Biological Support (\#77-NRMS), WeLEAD (NSF seed grant SBE-0620073), and Idaho State University. Protocols were approved by the ISU Institutional Animal Care and Use Committee (\#610). Any use of trade, product, or firm names is for descriptive purposes only and does not imply endorsement by the US Government.

\section{LITERATURE CITED}

Allison PD (1995) Survival analysis using SAS: a practical guide. SAS Institute, Cary, NC

Andre SE, Parker J, Briggs CJ (2008) Effect of temperature on host response to Batrachochytrium dendrobatidis infection in the mountain yellow-legged frog (Rana muscosa). J Wildl Dis 44:716-720

Annis SL, Dastoor FP, Ziel H, Daszak P, Longcore JE (2004) A DNA-based assay identifies Batrachochytrium dendrobatidis in amphibians. J Wildl Dis 40:420-428

Bartelt PE, Peterson CR, Klaver RW (2004) Sexual differences in the post-breeding movements and habitats selected by western toads (Bufo boreas) in southeastern Idaho. Herpetologica 60:455-467

Berger L, Speare R, Hines HB, Marantelli G and others (2004) Effect of season and temperature on mortality in amphibians due to chytridiomycosis. Aust Vet J 82:434-439

Brem FMR, Lips KR (2008) Batrachochytrium dendrobatidis infection patterns among Panamanian amphibian species, habitats and elevations during epizootic and enzootic stages. Dis Aquat Org 81:189-202

Briggs CJ, Knapp RA, Vredenburg VT (2010) Enzootic and epizootic dynamics of the chytrid fungal pathogen in amphibians. Proc Natl Acad Sci USA 107:9695-9700

Bustamante HM, Livo LJ, Carey C (2010) Effects of temperature and hydric environment on survival of the Panamanian golden frog infected with a pathogenic chytrid fungus. Integrative Zool 5:143-153

Carey C (1978) Factors affecting body temperatures of toads. Oecologia 35:197-208

Carey C, Cohen N, Rollins-Smith L (1999) Amphibian declines: an immunological perspective. Dev Comp Immunol 23:459-472
Carey C, Bruzgul JE, Livo LJ, Walling ML and others (2006) Experimental exposures of boreal toads (Bufo boreas) to a pathogenic chytrid fungus (Batrachochytrium dendrobatidis). EcoHealth 3:5-21

Corn PS (2007) Amphibians and disease: implications for conservation in the Greater Yellowstone Ecosystem. Yellowstone Sci 15:11-16

Goebel AM, Ranker TA, Corn PS, Olmstead RG (2009) Mitochondrial DNA evolution in the Anaxyrus boreas species group. Mol Phylogenet Evol 50:209-225

Hammerson GA (1999) Amphibians and reptiles in Colorado, 2nd edn. University of Colorado Press and Colorado Division of Wildlife, Boulder, CO

> Harris RN, James TY, Lauer A, Simon MA, Patel A (2006) Amphibian pathogen Batrachochytrium dendrobatidis is inhibited by cutaneous bacteria of amphibian species. EcoHealth 3:53-56

Hawk JE (2000) Amphibian declines in the Greater Yellowstone Ecosystem: Do thermally influenced waters protect boreal toads from bacterial disease? MS dissertation, Idaho State University, Pocatello, ID

Hossack BR, Eby LA, Guscio CG, Corn PS (2009) Thermal characteristics of toad microhabitats on a patchy landscape: potential benefits from wildfire. For Ecol Manag 258:1414-1421

Hutchison VH, Dupré RK (2002) Thermoregulation. In: Feder ME, Burggren WW (eds) Environmental physiology of the amphibians. University of Chicago Press, Chicago, IL, p 206-249

Johnson ML, Berger L, Philips L, Speare R (2003) Fungicidal effects of chemical disinfectants, UV light, desiccation and heat on the amphibian chytrid Batrachochytrium dendrobatidis. Dis Aquat Org 57:255-260

Kirshtein JD, Anderson CW, Wood JS, Longcore JE, Voytek MA (2007) Quantitative PCR detection of Batrachochytrium dendrobatidis DNA from sediments and water. Dis Aquat Org 77:11-15

Kluger MJ (1978) The evolution and adaptive value of fever. Am Sci 66:38-43

Kriger KM, Hero JM (2007) The chytrid fungus Batrachochytrium dendrobatidis is non-randomly distributed across amphibian breeding habitats. Divers Distrib 13: $781-788$

Lamirande EW, Nichols DK (2002) Effects of host age on the susceptibility to cutaneous chytridiomycosis in blue-andyellow poison dart frogs (Dendrobates tinctorius). In: McKinnell RG, Carlson DL (eds) 6th Int Symp Pathol Reptiles Amphibians, Saint Paul, MN, p 3-13

Lips KR, Reeve JD, Witters LR (2003) Ecological traits predicting amphibian population declines in Central America. Conserv Biol 17:1078-1088

Longcore JE, Pessier AP, Nichols DK (1999) Batrachochytrium dendrobatidis gen. et sp. nov., a chytrid pathogenic to amphibians. Mycologia 91:219-227

> Longcore JR, Longcore JE, Pessier AP, Halteman WA (2007) Chytridiomycosis widespread in anurans of northeastern United States. J Wildl Manag 71:435-444

Marcum RD, St-Hilaire S, Murphy PJ, Rodnick KJ (2010) Effects of Batrachochytrium dendrobatidis infection on ion concentrations in the boreal toad Anaxyrus (Bufo) boreas boreas. Dis Aquat Org 91:17-21

Matutte B, Storey KB, Knoop FC, Conlon JM (2000) Induction of synthesis of an antimicrobial peptide in the skin of the freeze-tolerant frog, Rana sylvatica, in response to environmental stimuli. FEBS Lett 483:135-138

McDonald KR, Méndez D, Müller R, Freeman AB, Speare R (2005) Decline in the prevalence of chytridiomycosis in 
frog populations in North Queensland, Australia. Pac Conserv Biol 11:114-120

Murphy PJ, St-Hilaire S, Bruer S, Corn PS, Peterson CR (2009) Distribution and pathogenicity of Batrachochytrium dendrobatidis in boreal toads from the Grand Teton area of western Wyoming. EcoHealth 6:109-120

Murray KA, Skerratt LF, Speare R, McCallum H (2009) Impact and dynamics of disease in species threatened by the amphibian chytrid fungus, Batrachochytrium dendrobatidis. Conserv Biol 23:1242-1252

Muths E, Corn PS, Pessier AP, Green DE (2003) Evidence for disease-related amphibian decline in Colorado. Biol Conserv 110:357-365

Padgett-Flohr GE (2008) Pathogenicity of Batrachochytrium dendrobatidis in two threatened California amphibians: Rana draytonii and Ambystoma californiense. Herpetol Conserv Biol 3:182-191

Pilliod DS, Muths E, Scherer RD, Bartelt PE and others (2010) Effects of the amphibian chytrid fungus on toad survival. Conserv Biol 24:1259-1267

Piotrowski JS, Annis SL, Longcore JE (2004) Physiology of Batrachochytrium dendrobatidis, a chytrid pathogen of amphibians. Mycologia 96:9-15

Pounds JA, Bustamante MR, Coloma LA, Consuegra JA and others (2006) Widespread amphibian extinctions from epidemic disease driven by global warming. Nature 439 : 161-167

Ramsey JP, Reinert LK, Harper LK, Woodhams DC, RollinsSmith LA (2010) Immune defenses against Batrachochytrium dendrobatidis, a fungus linked to global amphibian declines, in the South African clawed frog, Xenopus laevis. Infect Immun 78:3981-3992

Richards-Zawacki CL (2009) Thermoregulatory behaviour affects prevalence of chytrid fungal infection in a wild population of Panamanian golden frogs. Proc R Soc B 277: $519-528$

Richmond JQ, Savage AE, Zamudio KR, Rosenblum EB (2009) Toward immunogenetic studies of amphibian chytridio-

Editorial responsibility: Cynthia Carey,

Boulder, Colorado, USA mycosis: linking innate and acquired immunity. Bioscience 59:311-320

Rollins-Smith LA, Carey C, Longcore J, Doersam JK, Boutte A, Bruzgal JE, Conlon JM (2002) Activity of antimicrobial skin peptides from ranid frogs against Batrachochytrium dendrobatidis, the chytrid fungus associated with global amphibian declines. Dev Comp Immunol 26:471-479

Rollins-Smith LA, Ramsey JP, Reinert LK, Woodhams DC, Livo LJ, Carey C (2009) Immune defenses of Xenopus laevis against Batrachochytrium dendrobatidis. Front Biosci $\mathrm{S} 1: 68-91$

Rosenblum EB, Poorten TJ, Settles M, Murdoch GK, Robert J, Maddox N, Eisen MB (2009) Genome-wide transcriptional response of Silurana (Xenopus) tropicalis to infection with the deadly chytrid fungus. PLoS ONE 4:e6494

Rowley JJL, Alford RA (2007) Non-contact infrared thermometers can accurately measure amphibian body temperatures. Herpetol Rev 38:308-311

Skerratt LF, Berger L, Speare R, Cashins S and others (2007) Spread of chytridiomycosis has caused the rapid global decline and extinction of frogs. EcoHealth 4:125-134

Voyles J, Young S, Berger L, Campbell C and others (2009) Pathogenesis of chytridiomycosis, a cause of catastrophic amphibian declines. Science 326:582-585

> Woodhams DC, Alford RA (2005) Ecology of chytridiomycosis in rainforest stream frog assemblages of tropical Queensland. Conserv Biol 19:1449-1459

Woodhams DC, Alford RA, Marantelli G (2003) Emerging disease of amphibians cured by elevated body temperature. Dis Aquat Org 55:65-67

Woodhams DC, Voyles J, Lips KR, Carey C, Rollins-Smith LA (2006) Predicted susceptibility in a Panamanian amphibian assemblage based on skin peptide defenses. J Wildl Dis 42:207-218

Woodhams DC, Ardipradja K, Alford RA, Marantelli G, Reinert LK, Rollins-Smith LA (2007) Resistance to chytridiomycosis varies among amphibian species and is correlated with skin peptide defenses. Anim Conserv 10:409-417

Submitted: December 10, 2009; Accepted: January 13, 2011 Proofs received from author(s): May 10, 2010 